\title{
Efectividad en reducción de unidades formadoras de colonias con soluciones desinfectantes en tina ultrasónica.
}

\author{
Effectiveness in reducing colony forming units with \\ disinfecting solutions in an ultrasonic vat.
}

Juan Francisco Hernández Hernández,* Diego Armando Azcona Bravo*

\section{RESUMEN}

En la práctica clínica, los odontólogos se encuentran expuestos al riesgo de infecciones, que se transmiten a través de instrumentos contaminados con exudados. Instrumentos en contacto con el personal deben estar esterilizados o sometidos a un proceso de desinfección. Se realizó un estudio transversal-prospectivo a 30 pacientes, de los que se tomaron tres muestras con espejos estériles, pasando por fondo de saco, carrillos y lengua, después las muestras se desinfectaron, se realizó el hisopado de cada espejo y se incubó en agar tripticaseína-soya (TSA) 24 horas a 37 oC. Pasadas 24 horas se realizaron diluciones en tubos Eppendorf, y se sembraron en cajas de Petri con agar sangre, se incubaron por 48 horas a 37 oC; se contabilizaron las unidades formadoras de colonias (UFC) y registraron para su análisis. Al obtener los resultados se encontró que ID 213 tuvo mayor reducción con una media $=62.5$ en comparación con Zeta 1 Ultra, media $=89.23$, y control, media $=164.50$, de igual manera se observó una diferencia en reducción de UFC/mL entre ID 213 con respecto a Zeta 1 Ultra con significancia de 0.012. Ambos desinfectantes resultaron efectivos, pero se estableció que ID 213 utilizando la tina ultrasónica resulta más efectivo en la reducción de UFC, que Zeta 1 Ultra.

Palabras clave: Desinfectantes, reducción, tina ultrasónica, efectividad.

\section{ABSTRACT}

In clinical practice, dentists are exposed to the risk of infections, which are transmitted through instruments contaminated with exudates. Instruments in contact with personnel must be sterilized or subjected to a disinfection process. A cross-sectional-prospective study was carried out in 30 patients. From which three samples were taken with sterile mirrors, passing through cul-de-sac, cheeks and tongue, later the samples were disinfected with disinfectants, each mirror was swabbed and incubated in TSA 24 hours at $37^{\circ} \mathrm{C}$. After 24 hours, dilutions were made in Eppendorf tubes, and they were seeded in Petri dishes with blood agar, they were incubated 48 hours at $37^{\circ} \mathrm{C}$; CFUs were accounted for and recorded for analysis. When obtaining the results, it was found that ID 213 had a greater reduction with mean $=62.5$ compared to Zeta 1 Ultra mean $=89.23$ and control mean $=164.50$, in the same way a difference in reduction of CFU/mL was observed between ID 213 with respect to Zeta 1 Ultra with significance of 0.012 . Both disinfectants were effective but it was established that ID 213 using the ultrasonic tub is more effective in reducing CFU, than Zeta 1 Ultra.

Keywords: Disinfectants, reduction, ultrasonic tub, effectiveness.

\section{INTRODUCCIÓN}

$E^{\prime}$ I presente trabajo de investigación es un referente de la metodología que debe llevarse en la desinfección de instrumental odontológico con el uso de la tina ultrasónica.

Desde que se observaron por primera vez microorganismos a partir de muestras de placa dental humana, se le ha relacionado con el estado de salud/enfermedad de la cavidad oral. ${ }^{1}$

Malo $^{2}$ menciona que, en la práctica clínica, el odontólogo y el paciente se encuentran frecuentemente expuestos al riesgo de infección, debido a que la mayoría se transmiten a través de instrumentos y equipos contaminados con sangre, saliva o exudados. Todos

\footnotetext{
* Cirujano Dentista. Escuela Militar de Odontología. México.

Recibido: 20 de agosto de 2020. Aceptado: 13 de julio de 2021.
}

Citar como: Hernández HJF, Azcona BDA. Efectividad en reducción de unidades formadoras de colonias con soluciones desinfectantes en tina ultrasónica. Rev ADM. 2021; 78 (6): 339-345. https://dx.doi.org/10.35366/102975 
los materiales o instrumentos que tienen contacto con el paciente y el personal deben estar esterilizados o sometidos a un proceso de limpieza y desinfección, con agentes apropiados que garanticen la reducción o eliminación de contaminantes. El conocimiento sobre los microorganismos y los hábitos de bioseguridad han cambiado radicalmente con el propósito de controlar las infecciones. ${ }^{3}$

Vivero ${ }^{4}$ realizó la comparación entre el Lysol y el glutaraldehído a $2 \%$ por el mismo tiempo de exposición y concluyó en que el Lysol tuvo una reducción significativa en comparación al glutaraldehído. Lozano ${ }^{5}$ observó en sus resultados generales el crecimiento bacteriano mediante la aplicación de glutaraldehído a $2 \%$, en donde la reducción promedio de unidades formadoras de colonias (UFC) fue menor a $50 \%$.

El odontólogo es el primer responsable de evitar la infección cruzada mediante un correcto dominio y aplicación de los conocimientos de bioseguridad respecto al uso de barreras, procesos de desinfección y esterilización. Es por este motivo que el siguiente trabajo de investigación comparó mediante conteo de UFC la eficacia entre dos desinfectantes usados en odontología para determinar cuál de éstos es la mejor opción para la desinfección del instrumental.

\section{MATERIAL Y MÉTODOS}

Se realizó un estudio transversal-prospectivo en la Escuela Militar de Odontología a 30 pacientes, de los que se tomaron tres muestras con espejos estériles, pasando por fondo de saco, carrillos y lengua, después las muestras se desinfectaron de acuerdo con la indicación de los fabricantes (ID 213 al $2 \%$ [20 mL/L] por 2 min y Zeta 1 Ultra a $1 \%$ [10 $\mathrm{mL} / \mathrm{L}]$ por $15 \mathrm{~min}$ ) y una muestra control con agua bidestilada, se realizó el hisopado de cada espejo y se incubó en medio agar tripticaseínasoya (TSA) 24 horas a $37^{\circ} \mathrm{C}$. Pasadas las 24 horas se realizaron diluciones seriadas en tubos Eppendorf, y se sembraron en cajas de Petri con agar sangre con la técnica de siembra en superficie, se incubaron 24 horas a $37^{\circ} \mathrm{C}$; se contabilizaron las UFC con el contador de colonias y registraron para su análisis.

\section{RESULTADOS}

En el presente estudio se analizaron 99 muestras, de las cuales tres muestras de cada grupo resultaron contaminadas por haber estado mal cerradas en las cajas de cultivo, por lo que quedaron 90 muestras divididas en tres grupos, dando un total de 30 muestras por grupo (grupo control,

\begin{tabular}{|c|c|c|c|}
\hline Definición conceptual & Definición operacional & $\begin{array}{l}\text { Tipo de } \\
\text { variable }\end{array}$ & $\begin{array}{l}\text { Escala de } \\
\text { medición }\end{array}$ \\
\hline $\begin{array}{l}\text { Los desinfectantes son productos químicos que se } \\
\text { aplican sólo en objetos inanimados con el fin de } \\
\text { eliminar microorganismos patógenos de su superficie }\end{array}$ & $\begin{array}{l}\text { Su eficacia estriba en que } \\
\text { desnaturaliza las proteínas } \\
\text { e inactiva la envoltura } \\
\text { lipídica de los virus }\end{array}$ & $\begin{array}{c}\text { Cualitativa } \\
\text { nominal }\end{array}$ & $\begin{array}{l}\text { Nominal: } \\
\text { 1. Zeta } 1 \text { Ultra } \\
\text { 2. ID } 213\end{array}$ \\
\hline
\end{tabular}

Tabla 2: Variable dependiente: unidades formadoras de colonias (UFC).

\begin{tabular}{llll} 
Definición conceptual & Definición operacional & Tipo de variable & Escala de medición \\
\hline Término que debe utilizarse & Consiste en contar las & Cuantitativa continua & Razón: \\
para reportar la cuenta de & colonias, que se desarrollan & & UFC/mL \\
colonias en placa, las cuales & en el medio de elección & & \\
pueden surgir de una célula & después de un cierto tiempo & & \\
o de un cúmulo de células & y temperatura de incubación, & & \\
& utilizando un contador de UFC & \\
\hline
\end{tabular}


Tabla 3: Cantidad y costos de recursos humanos, físicos y materiales.

\begin{tabular}{rlr} 
Cantidad & Productos & Precio (MXN) \\
\hline 10 & Solución Zeta 1 Ultra & 13,230 \\
10 & Solución ID 213 & 11,970 \\
1 & Tina ultrasónica GNATUS & 998 \\
5 & Espejos No. 5 Hu-Friedy & 1,620 \\
5 & Caja de guantes estériles & 500 \\
2 & Paquete de tubos de ensayo & 614 \\
1 & Contenedor de medio & 1,498 \\
& de transporte TSB & 3,970 \\
10 & Cajas de medio agar sangre & 960 \\
150 & Cajas de Petri & 500 \\
10 & Agua bidestilada & 25,160
\end{tabular}

desinfectante Zeta 1 y ultra desinfectante ID 213), obteniendo los siguientes resultados (Tablas 1 a 9).

Se compararon dos tipos de desinfectantes, ambos para tina ultrasónica, el primero ID 213; el segundo Zeta 1 Ultra y un grupo control, en el cual sólo se utilizó la tina ultrasónica.

Se encontró que el desinfectante ID 213 tuvo una mayor reducción (media $=62.5$ ), en comparación con otro desinfectante (Zeta 1 Ultra, media $=89.23$ ) y el grupo control $($ media $=164.50)($ Figuras 1 y 2 ).

\section{DISCUSIÓN}

Una consulta odontológica involucra una serie de riesgos en la cual se recomienda considerar a todos los pacientes como portadores de agentes infecciosos. Los protocolos de bioseguridad deben ser aplicados en todos los tratamientos odontológicos para evitar la contaminación cruzada entre pacientes; sin embargo, si estos protocolos no son debidamente realizados en instrumentos y equipos odontológicos, el riesgo de contaminación cruzada se incrementa, lo cual puede afectar a todas las personas involucradas en la atención odontológica. ${ }^{6-8}$

La prevención y el control de infecciones son de gran importancia a la hora de brindar un servicio médico seguro. El riesgo de transmisión de patógenos en medio odontológico se ha estimado mayor al de otros entornos clínicos. Los microorganismos pueden transmitirse de manera directa (mediante el contacto físico entre pa- cientes o entre un paciente y el personal sanitario), de manera indirecta (mediante el contacto con instrumentos o superficies contaminadas) y por medio de aerosoles (debido a la exposición a gotas procedentes de toses o estornudos). 9,10

\begin{tabular}{|c|c|c|c|}
\hline \multirow[b]{2}{*}{ Paciente } & \multicolumn{3}{|c|}{ Grupo, UFC } \\
\hline & Control & $\begin{array}{l}\text { Desinfectante } \\
\text { Zeta } 1 \text { Ultra }\end{array}$ & $\begin{array}{c}\text { Desinfectante } \\
\text { Dürr ID } 213\end{array}$ \\
\hline 1 & 79 & 43 & 28 \\
\hline 2 & 85 & 51 & 28 \\
\hline 3 & 85 & 55 & 29 \\
\hline 4 & 98 & 55 & 32 \\
\hline 5 & 107 & 63 & 35 \\
\hline 6 & 109 & 65 & 37 \\
\hline 7 & 122 & 68 & 39 \\
\hline 8 & 123 & 68 & 46 \\
\hline 9 & 141 & 72 & 47 \\
\hline 10 & 151 & 73 & 48 \\
\hline 11 & 152 & 78 & 49 \\
\hline 12 & 153 & 84 & 50 \\
\hline 13 & 153 & 84 & 52 \\
\hline 14 & 156 & 88 & 53 \\
\hline 15 & 158 & 92 & 54 \\
\hline 16 & 159 & 93 & 55 \\
\hline 17 & 163 & 96 & 56 \\
\hline 18 & 173 & 96 & 63 \\
\hline 19 & 179 & 100 & 64 \\
\hline 20 & 183 & 103 & 70 \\
\hline 21 & 192 & 105 & 73 \\
\hline 22 & 201 & 106 & 74 \\
\hline 23 & 202 & 108 & 77 \\
\hline 24 & 218 & 111 & 78 \\
\hline 25 & 221 & 111 & 96 \\
\hline 26 & 227 & 115 & 97 \\
\hline 27 & 228 & 119 & 100 \\
\hline 28 & 233 & 124 & 102 \\
\hline 29 & 237 & 124 & 122 \\
\hline 30 & 247 & 127 & 123 \\
\hline Total & 4,935 & 2,677 & 1,877 \\
\hline
\end{tabular}

UFC = unidades formadoras de colonias. 
Tabla 5: Descriptivos de la media y desviación estándar de la efectividad en reducción de UFC con los desinfectantes con tina ultrasónica.

\begin{tabular}{lrrr} 
& $\mathrm{n}$ & Media & \multicolumn{1}{l}{ DE } \\
\hline Dürr ID 213 & 30 & 62.57 & 26.945 \\
Zeta 1 Ultra & 30 & 89.23 & 23.857 \\
Control & 30 & 164.50 & 49.291 \\
Total & 90 & 105.43 & 55.656 \\
\hline
\end{tabular}

UFC = unidades formadoras de colonias; DE = desviación estándar.

\begin{tabular}{lcc}
\multicolumn{3}{c}{ Tabla 6: ANOVA de un factor. } \\
& gl & Sig. \\
\hline Inter-grupos & 2 & 0.000 \\
Intra-grupos & 87 & \\
Total & 89 & \\
\hline p = 0.000 menor al margen de error que es de 0.050, por lo tanto, hay \\
una significancia entre los grupos de estudio.
\end{tabular}

Estudios similares al nuestro han comparado diversos desinfectantes de instrumental y material odontológico, utilizando metodologías parecidas a la ocupada en esta investigación, obteniendo los siguientes resultados.

Acuña ${ }^{11}$ en su estudio determinó la efectividad antimicrobiana in vitro del alcohol a $70 \%$ y del glutaraldehído a $2 \%$, utilizado en la superficie externa de las piezas de mano de alta velocidad. El alcohol a 70\% presentó mayor efectividad antimicrobiana in vitro en comparación con el glutaraldehído a $2 \%$, al ser utilizados en la superficie externa de las piezas de mano de alta velocidad de uso odontológico.

Iturralde ${ }^{12}$ comprobó que las sustancias desinfectantes a base de etanol (alcohol etílico) no son suficientes para realizar una adecuada desinfección de superficies. Santos $^{13}$ evaluó la desinfección con el uso de hipoclorito de sodio a $5.25 \%$, demostrando que en un minuto reduce la carga microbiológica mientras que a $0.52 \%$ la reduce a los 10 minutos.

Vivero ${ }^{4}$ realizó la comparación entre el Lysol y el glutaraldehído a $2 \%$ por el mismo tiempo de exposición y concluyó en que el Lysol tuvo una reducción signifi- cativa. Lozano ${ }^{5}$ observó en sus resultados generales el crecimiento bacteriano de glutaraldehído a $2 \%$, en donde la reducción promedio de UFC fue de menos de $50 \%$.

Acosta y colaboradores ${ }^{14}$ confirmaron que el cloruro de benzalconio carece de actividad esporicida y ratifican que este compuesto cuaternario de amonio no tiene aplicación como agente esterilizante o como desinfectante de instrumental médico y dental.

Sattar ${ }^{15}$ observó que su mejor método de desinfección fue el cloro y compuestos del cloro, como el hipoclorito de sodio 5.25-6.15\%, el cual a una concentración de 100-5,000 ppm de cloro era altamente bactericida pero altamente corrosivo con los materiales.

Los autores mencionados anteriormente realizaron estudios sobre la efectividad de sustancias desinfectantes en diferentes materiales e instrumentos dentales, obteniendo diferentes resultados en cada uno de ellos y ocupando un método similar al de nuestra investigación.

Ganavadiya y colegas ${ }^{16}$ explicaron que los entornos de atención dental están asociados con un riesgo de exposición a microorganismos, tanto para trabajadores

Tabla 7: Pruebas robustas de igualdad de las medias.

\begin{tabular}{lccc} 
& gl1 & gl2 & Sig. \\
\hline Welch & 2 & 54.852 & 0.000 \\
Brown-Forsythe & 2 & 59.572 & 0.000 \\
\hline
\end{tabular}

Se muestra la significancia entre los desinfectantes y el grupo control. Significancia menor a 0.050 para aceptar hipótesis de trabajo.

Tabla 8: Comparaciones múltiples.

\begin{tabular}{lll}
\multicolumn{2}{c}{ HSD de Tukey } & Sig. \\
\hline \multirow{2}{*}{ Dürr ID 213 } & Zeta 1 Ultra & 0.012 \\
& Control & 0.000 \\
\multirow{2}{*}{ Zeta 1 Ultra } & Dürr ID 213 & 0.012 \\
& Control & 0.000 \\
Control & Dürr ID 213 & 0.000 \\
& Zeta 1 Ultra & 0.000 \\
\hline
\end{tabular}

Se utilizó HSD (diferencia honestamente significativa, por sus siglas en inglés) de Tukey para hacer la comparación de los grupos y obtener la significancia entre un grupo y otro. 
Tabla 9: Subconjuntos homogéneos.

\begin{tabular}{|c|c|c|c|c|}
\hline \multirow[b]{2}{*}{ HSD de Tukey } & \multirow[b]{2}{*}{$\mathrm{N}$} & \multicolumn{3}{|c|}{ Subconjunto para alfa $=0.050$} \\
\hline & & 1 & 2 & 3 \\
\hline Dürr ID 213 & 30 & 62.57 & & \\
\hline Zeta 1 Ultra & 30 & & 89.23 & \\
\hline Control & 30 & & & 164.50 \\
\hline Sig. & & 1.000 & 1.000 & 1.000 \\
\hline
\end{tabular}

Se muestra que los tres grupos estudiados son heterogéneos, la significancia entre ellos y la diferencia de la varianza es muy marcada en cada grupo.

dentales como para sus pacientes. Los peligros microbiológicos implican una gran cantidad de microorganismos detectados en saliva y fluidos gingivales, así como en instrumentos dentales contaminados.

Takahashi ${ }^{17}$ menciona que la cavidad bucal de los pacientes es la mayor fuente de infección a la que los profesionales de odontología están expuestos, la American Dental Association (ADA) recomienda considerar a todos los casos que acuden a la consulta odontológica como portadores de agentes infecciosos. Para una práctica preventiva y segura de la odontología, es fundamental comprender los principios básicos de la esterilización y la desinfección para contribuir a evitar la infección cruzada.

Los estudios realizados por Vázquez y colegas. ${ }^{10}$ en una universidad de Ecuador identifican que la mitad de los estudiantes observados utilizan agentes desinfectantes. Mientras que, en el estudio de Hoyos y Gutiérrez ${ }^{18}$ se observó que la mayoría de los estudiantes presenta un conocimiento regular acerca de los métodos de limpieza y desinfección del instrumental. Los procedimientos odontológicos conllevan un riesgo potencial de transmisión de enfermedades infecciosas que probablemente se ha subestimado, por lo que es imperativo adoptar protocolos eficaces de prevención de la infección cruzada.

Romero y colaboradores ${ }^{19}$ realizaron un estudio para comparar la eficacia entre la limpieza manual y la limpieza ultrasónica en limas endodónticas, demostraron que ambas técnicas tienen la misma efectividad para la completa remoción de restos biológicos en limas (tipo K). También que existe un riesgo de lesiones por pinchazo con limas en el protocolo de limpieza manual y que por lo tanto es más seguro y más factible la limpieza ultrasónica. Para la limpieza manual se requiere instruir al personal que se encarga de la limpieza del instrumental acerca de la técnica de cepillado, existiendo el riesgo de accidentes por pinchazo. La limpieza ultrasónica es un método seguro en cuanto a accidentes y sobre todo muy cómodo, puesto que se deja el instrumental en la tina 30 minutos y permite a quien se encargue de la limpieza realizar otras tareas.

Abarca ${ }^{20}$ realizó una revisión sistemática para analizar la evidencia sobre la eficacia del lavado manual comparado con el lavado automático en la limpieza del instrumental médico quirúrgico. En la selección definitiva se eligieron 10 artículos, encontramos que $80 \%$ afirma que el lavado automático resulta más eficaz que el lavado manual, asimismo $10 \%$ indica que el lavado manual es eficaz, del mismo modo 10\% indica que el lavado manual y automatizado resulta eficaz en la limpieza del instrumental. En conclusión, se evidenció en las investigaciones revisadas que existe eficacia en el lavado automatizado, reduciendo así la carga bacteriana y siendo más segura para lograr un adecuado procedimiento de esterilización; se ha informado que existe eficacia en el lavado automatizado, reduciendo así la carga bacteriana y siendo más segura para lograr un adecuado procedimiento de esterilización.

En este trabajo nos propusimos determinar la efectividad en reducción de UFC de dos soluciones desinfectantes en tina ultrasónica. Partimos de la hipótesis de ver si existe diferencia entre la efectividad de la solución desinfectante de instrumental odontológico, ID 213 y Zeta 1 Ultra. Lo anterior en virtud de que una de las formas

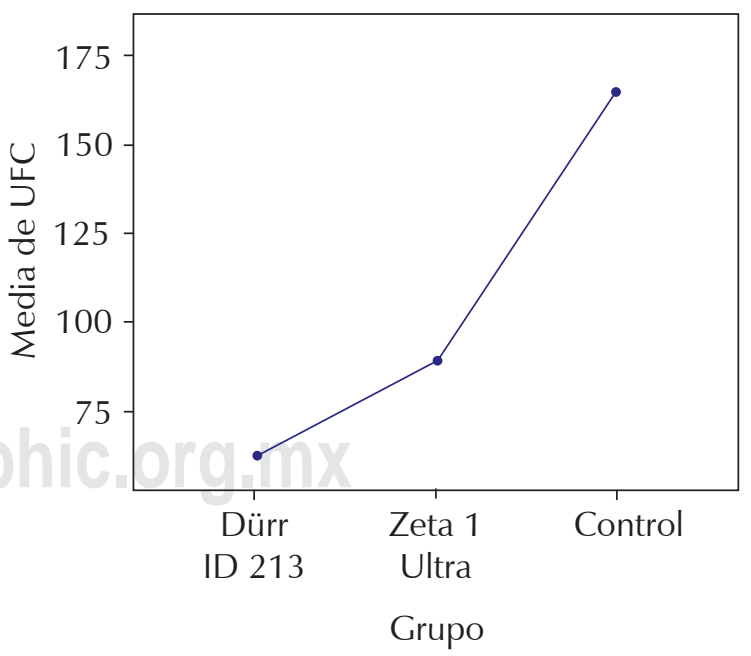

Figura 1: Gráfica lineal que representa la media de los grupos estudiados. UFC = unidades formadoras de colonias. 


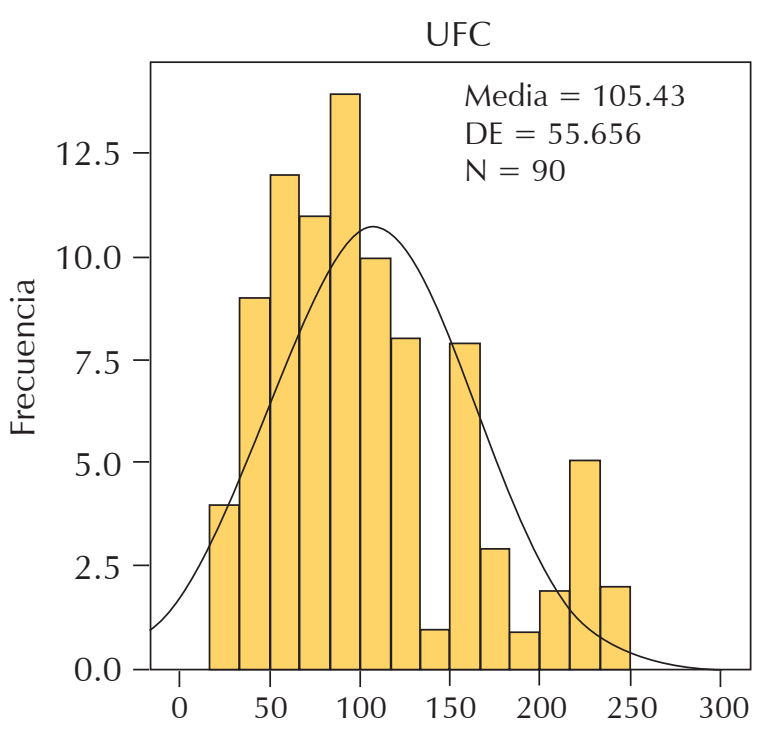

Figura 2: Grafica de normalidad en la cual podemos observar que la distribución del estudio es normal. UFC = unidades formadoras de colonias. DE = desviación estándar.

más importantes de prevenir las infecciones cruzadas es con el uso de desinfectantes.

Al realizar este estudio con ambos desinfectantes, contaban con componentes muy similares y su principal sustancia activa son las sales de amonio cuaternario y alquilaminas, la solución desinfectante Zeta 1 Ultra posee sustancias que ayudan a combatir la corrosión del instrumental, se ocuparon conforme a las indicaciones del fabricante, $10 \mathrm{~mL} / \mathrm{L}$ en un tiempo de 15 minutos con Zeta 1 Ultra y $20 \mathrm{~mL} / \mathrm{L}$ por 2 minutos con ID 213, ambos con ayuda de la tina ultrasónica, resultando más efectiva la solución desinfectante ID 213, y el espectro de acción de acuerdo con la información del fabricante es mayor con el desinfectante ID 213.

La esterilización y desinfección de artículos de uso clínico constituyen eficientes mecanismos para la prevención de infecciones asociadas a las atenciones de salud. Los profesionales de la salud deben conocer el instrumental que manejan y los productos empleados en su descontaminación, por lo que al limpiar, desinfectar o esterilizar productos sanitarios se adquiere una responsabilidad legal que obliga a garantizar la correcta ejecución de estos procesos.

\section{CONCLUSIONES}

A partir de los resultados obtenidos en esta investigación, se acepta hipótesis de trabajo, ya que existe una diferencia en la reducción de unidades formadoras de colonias con la utilización de desinfectantes y el uso de la tina ultrasónica.

1. Se determinó que existe mayor efectividad en la reducción de UFC entre el desinfectante Zeta 1 Ultra con respecto al grupo control.

2. Existe una mayor efectividad en la reducción de UFC entre el desinfectante ID 213 con respecto al grupo control.

3. Se compararon y se obtuvo una mayor efectividad en la reducción de UFC entre el desinfectante ID 213 con respecto al desinfectante Zeta 1 Ultra.

4. Se estableció que el desinfectante ID 213 utilizando la tina ultrasónica resulta más efectivo en la reducción de UFC, en comparación con el desinfectante Zeta 1 Ultra.

5. Por consiguiente, el empleo del desinfectante ID 213 es la mejor opción para el uso en el instituto armado, debido a que tienen un menor costo respecto al desinfectante Zeta 1 Ultra y consigue un mayor beneficio en su nivel de desinfección.

6. El desinfectante ID 213 cuenta en menor medida con sustancias que sirven para evitar la corrosión del instrumental, tales como las sales de amonio cuaternario; sin embargo, reduce en mayor medida y en menor tiempo las UFC con el uso de la tina ultrasónica.

7. Por lo tanto, el desinfectante ID 213 proporciona una mayor seguridad en el entorno odontológico, proporcionando una mayor efectividad, menor costo y tiempo en la desinfección del instrumental odontológico.

Con el fin de que se continúe la línea de investigación, recomendamos determinar el tipo de microorganismos que se observan en la cavidad oral antes y después de una desinfección con el uso de la tina ultrasónica.

\section{REFERENCIAS}

1. Serrano-Coll HA, Sánchez-Jiménez M, Cardona-Castro N. Conocimiento de la microbiota de la cavidad oral a través de la metagenómica. CES Odontol. 2015; 28 (2): 112-118.

2. Calva Malo ME. Análisis comparativo del efecto desinfectante entre el alcohol etílico $80 \%$ y etanol $58 \%$ sobre turbina y micromotor, realizado en la clínica de octavo y noveno semestre de la Facultad de Odontología de la Universidad Central del Ecuador, período 2015-2016 [Tesis]. Quito: UCE; 2016.

3. Evangelista SS, Dos Santos SG, De Resende Stoianoff MA, de Oliveira AC. Analysis of microbial load on surgical instruments after clinical use and following manual and automated cleaning. Am J Infect Control. 2015; 43 (5): 522-527. 
4. Vivero Alcívar FA. Análisis microbiológico del nivel de desinfección del glutaraldehído al $2 \%$ y sacarinato de alquildimetilbencilamonio al 95\% en el instrumental crítico y semicrítico utilizado en la Clínica de Odontológica de la Universidad Internacional del Ecuador [Tesis]. Quito: Universidad Internacional del Ecuador; 2017.

5. Lozano Torres AR, Viteri Moya J, Izquierdo Buchelli AE. Efectividad de lysol y glutaraldehído al $2 \%$ en piezas de mano de alta velocidad después de ser sometidas a limpieza mecánica. Rev Odontol. 2019; 21 (1): 34-43.

6. Bustamante Andrade MF, Herrera Machuca J, Ferreira Adam R, Riquelme Sánchez D. Contaminación bacteriana generada por aerosoles en ambiente odontológico. Int J Odontostomat. 2014; 8 (1): 99-105.

7. Blanco Ventura D. Manual de bioseguridad para consultorio odontológico. Bogotá, D.C.: Universidad Militar Nueva Granada; 2016.

8. Véliz E, Vergara T, Pearcy M, Dabanch J. Importancia del proceso de limpieza y desinfección de superficies críticas en un servicio dental. Impacto de un programa de intervención. Rev Chil Infectol. 2018; 35 (1): 88-90.

9. Rodríguez Uramis M, Arpajón Peña Y, Sosa Pérez AL. De la bioseguridad al control de infecciones en Estomatología. Rev Cubana Estomatol. 2014; 51 (2): 224-236.

10. Vázquez Rodríguez I, Gómez Suárez R, Estany-Gestal A, Mora Bermúdez MJ, Varela-Centelles P, Santana Mora U. Control de la infección cruzada en los laboratorios de prótesis dental de Galicia. Anales Sis San Navarra. 2018; 41 (1): 75-82.

11. Acuña A, Rodas R, Torres L. Efectividad antimicrobiana de dos desinfectantes utilizados en las piezas de mano de alta velocidad de uso odontológico. Estudio in vitro [Tesis]. Chiclayo: Universidad Católica Santo Toribio de Mogrovejo; 2015.

12. Iturralde Gamboa AV. Comparación del efecto desinfectante entre lysol y eucida en las superficies de las jeringas triples de las unidades Odontológicas de la clínica integral de séptimo semestre de la Facultad de Odontología de la Universidad Central del Ecuador [Tesis]. Quito: Universidad Central del Ecuador; 2015. pp. 85-112.

13. Santos-Junior AG, Ferreira AM, Frota OP, Rigotti MA, Barcelos LDS, Lopes de Sousa AF et al. Effectiveness of Surface Cleaning and Disinfection in a Brazilian Healthcare Facility. Open Nurs J. 2018; 12: 36-44. doi: 10.2174/1874434601812010036.

14. Acosta-Gío E, Herrero-Farías A, Mata-Portuguez VH. El cloruro de benzalconio: inaceptable para esterilizar o desinfectar instrumental médico o dental. Salud Pública Méx. 2001; 43 (6): 570-573.

15. Sattar S. Capítulo 12. Limpieza, desinfección y esterilización. En: Friedman C, Newsom W. Conceptos básicos de control de infecciones. N Ireland, UK: International Federation of Infection Control; 2015. pp. 183-202.

16. Ganavadiya R, Chandra Shekar BR, Saxena V, Tomar P, Gupta R, Khandelwal G. Disinfecting efficacy of three chemical disinfectants on contaminated diagnostic instruments: A randomized trial. J Basic Clin Pharm. 2014; 5 (4): 98-104.

17. Takahashi N. Oral microbiome metabolism: from "who are they?" to "what are they doing?". J Dent Res. 2015; 94 (12): 1628-1637.

18. Hoyos SM, Gutiérrez CLN. Esterilización, desinfección, antisépticos y desinfectantes. Rev Act Clin Med. 2014; 49: 2635-2640.

19. Romero MBR, Medina SKB, Guízar MJM, de Santos AJ. Comparación de la eficacia entre los diferentes métodos de limpieza para limas endodónticas. Rev ADM. 2015; 72 (3): 134-138.

20. Abarca DCM. Eficacia del lavado manual en comparación con el lavado automático en la limpieza del instrumental médico quirúrgico [Tesis]. Perú: Universidad Privada Norbert Wiener; 2018.

\section{Correspondencia:}

Diego Armando Azcona Bravo

E-mail: diegoazconab@gmail.com 